\title{
The study of xenacoelomorph nervous systems. Molecular and morphological perspectives
}

\author{
P. Martinez ${ }^{1,2}$, E. Perea-Atienza1 ${ }^{1}$ B. Gavilán ${ }^{1}$, \\ C. Fernandez ${ }^{1}$, S. Sprecher ${ }^{3}$
}

\begin{abstract}
${ }^{1}$ Departament de Genètica, Microbiologia I Estadistica, Universitat de Barcelona, Av. Diagonal, 645,E-08028Barcelona,Spain.e-mail:pedro.martinez@ub.edu elenap.atienza@gmail.com brenda.g.a@gmail.com camilafeza@gmail.com

${ }^{2}$ ICREA (Institut Català de Recerca i Estudis Avancats), Barcelona, Spain.

${ }^{3}$ Department of Biology, University of Fribourg, 10, ch. du Musée, 1700 Fribourg, Switzerland. Email: simon.sprecher@unifr.ch
\end{abstract}

ABSTRACT: The evolution of centralized nervous systems (NS) and complex brains are among the most important innovations in the history of life on our planet. Many of the major transitions in animal evolution have been accompanied by significant reorganization of the NS. For instance, during the emergence of bilaterians, the radial-bilateral transition (RBT) not only involved the innovation of orthogonal body axes - anteroposterior or AP; dorsoventral or DV - and of a third embryonic layer, the mesoderm, providing controlled motility, but also the emergence of neuronal aggregates at the anterior pole of the animal (some of these innovations, though, are seen already in the anthozoans). This mass of interconnected neurons allowed better-oriented control and response to external sensory inputs. In this context, several important general questions need to be addressed. What evolutionary changes in the mechanisms of development can lead to a centralized or conversely to a diffuse NS? What constitutes the minimal genetic toolkit for the development of a centralized NS (a brain)? All these questions belong to the realm of neurogeneticoriented basic research, and therefore, the human brain is treated just as one peculiar case (highly derived) of a centralized NS. To answer these questions, we have chosen to perform a developmental and genomic study of the phylum Xenacoelomorpha, because the different clades within this phylum show distinct degrees of nervous system centralization (from none to the presence of a ganglionic, true brain), and because we expect that the analysis of their NS will eventually be crucial to understand their phylogenetic position. An (speculative) evolutionary hypothesis for the origin of centralized nervous systems is proposed at the end of this manuscript.

How to cite this article: Martinez P., Perea-Atienza E., Gavilán B., Fernandez C., Sprecher S. 2017. The study of xenacoelomorph nervous systems. Molecular and morphological perspectives // Invert. Zool. Vol.14. No.1. P.32-44. doi: 10.15298/invertzool.14.1.06

KEY WORDS: Xenacoelomorpha, Xenoturbellida, Nemertodermatida, Acoela, Genome Evolution, Gene Families, Brain, Nerve Net, RNA Hypothesis, Origin Bilateria.

\footnotetext{
* Corresponding author
} 


\title{
Изучение нервной системы ксенацеломорф. Молекулярные и морфологические перспективы
}

\author{
П. Мартинез ${ }^{1,2}$, Е. Переа-Атиенза', Б. Гэвилан ${ }^{1}$, \\ К. Фернандез ${ }^{1}$, С. Спречер ${ }^{3}$
}

\author{
${ }^{1}$ Departament de Genètica, Microbiologia I Estadistica, Universitat de Barcelona, Av. Diagonal, \\ 645,E-08028Barcelona,Spain.e-mail:pedro.martinez@ub.edu elenap.atienza@gmail.com \\ brenda.g.a@gmail.com camilafeza@gmail.com \\ ${ }^{2}$ ICREA (Institut Català de Recerca i Estudis Avancats), Barcelona, Spain. \\ ${ }^{3}$ Department of Biology, University of Fribourg, 10, ch. du Musée, 1700 Fribourg, Switzerland. E- \\ mail: simon.sprecher@unifr.ch
}

РЕЗЮМЕ: Формирование централизованной нервной системы (NS) и сложного мозга - наиболее важные новшества в истории жизни нашей планеты. Многие важные события в эволюции животных сопровождались существенными реорганизациями нервной системы. Так, в эволюции билатерий переход от радиальной симметрии к билатеральной (RBT) сопровождался не только изменением ортогональных осей тела и появлением третьего зародышевого листка - мезодермы, обеспечившей контролируемое передвижение, но также и появлением нейрональных скоплений на переднем конце тела животного (некоторые из этих новшеств обнаруживаются уже у коралловых полипов). Появление скопления связанных друг с другом нейронов позволило существенно улучшить контроль ориентации в пространстве и ответ на внешние раздражители. В этом контексте необходимо прояснить некоторые важные вопросы. Какие эволюционные изменения механизмов развития могут привести к появлению централизованной нервной системы или, наоборот, диффузной нервной системы? Каков минимально необходимый набор генетических механизмов, требующихся для формирования централизованной нервной системы (мозга)? Эти вопросы относятся к области нейрогенетических фундаментальных исследований, а сложный мозг человека является одним из особых случаев чрезвычайного развития централизованной нервной системы. Для того, чтобы ответить на эти вопросы, мы изучили развитие и геномные особенности у представителей типа Хenacoelomorpha, поскольку они демонстрируют выраженные степени централизации нервной системы: от полного отсутствия нервных центров, до наличия настоящего мозга. Кроме того, выбирая объекты исследования, мы ожидали получить данные, позволяющие прояснить положение группы Хеnacoelomorpha на филогенетическом древе билатерий. Умозрительная гипотеза эволюции централизованной нервной системы описана в конце настоящей работы.

Как цитировать эту статью: Martinez P., Perea-Atienza E., Gavilán B., Fernandez C., Sprecher S. 2017. The study of xenacoelomorph nervous systems. Molecular and morphological perspectives // Invert. Zool. Vol.14. No.1. P.32-44. doi: 10.15298/ invertzool.14.1.06

КЛЮЧЕВЫЕ СЛОВА: Хenacoelomorpha, Xenoturbellida, Nemertodermatida, Acoela, эволюция генома, семейство генов, мозг, нервный плексус, гипотеза рецепторной и нейрональной агрегации, происхождение билатерий. 
The origin of centralized nervous systems has been a recurrent problem tackled by both neurobiologists and developmental biologists. We define here a centralized nervous system (NS) as an arrangement of nervous tissue that comprises distinct agglomerations of functionally specialized neurons (nuclei) interconnected by axon tracts (neuropil), performing integrative functions (Arendt et al., 2008). A major difficulty in building a reliable scenario for the origin of a centralized nervous system is the selection of proper biological models. During the last years and in our laboratories we are using as models the xenacoelomorphs, a clade known as the first offshoot of the bilaterians. Many genomic and transcriptomic tools are being used to study the functions of regulatory genes and the hierarchical levels that they control. Moreover, the activities of these genes are being systematically mapped in time and space using in situ hybridization and immunochemical methods. In parallel, a high-resolution 3D model of the acoel brain, made from electron microscopy images is being developed in several laboratories, giving us a view of the architecture of this nervous system at an unprecedented level of resolution (subcellular structures). Comparing how these expression patterns change over evolutionary time in different subsets of neurons and neuronal circuits should help us to understand the molecular underpinnings of the changes in xenacoelomorph neural architectures, from the simpler xenoturbellid nerve net to the more complex acoel brains. How this is being done needs, first of all, a good understanding of the problematics and the species being selected to deal with it. In the following paragraphs we develop the background needed.

\section{Xenacoelomorpha: The species se- lected}

The main focus of our research efforts has been the study of neurogenic gene batteries and their connected networks in the phylum Xenacoelomorpha. This is an enigmatic phylum composed of three major taxa: acoel flatworms, nemertodermatids, and xenoturbellids. The ear- liest branching clade within this phylum, the Xenoturbellida (Bourlat et al., 2006) was, until recently, only represented by two nominal species: Xenoturbella bocki (Westblad, 1949) and $X$. westbladi (Israelsson, 1999), though newly identified specimens have been collected from the Pacific (Rouse et al., 2016). These worms are notably larger than the acoelomorphs (Acoela plus Nemertodermatida) but share a relatively simple morphology with them. The Nemertodermatida consists of several species of marine worms (see: Meyer-Wachsmuth et al., 2014 for a recent assessment); while Acoela contains the majority of the phylum's species: over 380 . Acoels are mostly marine bilateral flatworms with a simple unsegmented body plan. They are triploblastic and acoelomate, with an outer epidermis of multiciliated cells and a single gut opening. They share some morphological features with nemertodermatids, such as epidermal ciliation, intestine organization, certain glandular and sensory structures, and the limited presence of an extracellular matrix (Raikova et al., 2004; see: Achatz et al., 2013 for a complete bibliography).

To date, all phylogenomic studies demonstrate that Xenacoelomorpha conform a clear monophyletic group, which allows us to study specific genomic and morphological patterns of diversification within it. The monophyly of Xenacoelomorpha is also supported by morphological similarities (Ehlers, 1985; Smith, Tyler, 1986; Lundin, Hendelberg, 1995; Lundin, 1997, 2000); for instance, the ultrastructure of the ciliary tips and the system of epidermal ciliary rootlets. The phylogenetic relation of Xenacoelomorpha to the rest of metazoan phyla is, however, still controversial. Recent phylogenomic analysis has found that Xenacoelomorpha is the earliest offshoot of the bilaterians (Hejnol et al., 2009; Cannon et al., 2016). However, a different study suggested that instead, Xenacoelomorpha represent a deuterostomian group sister to the Ambulacraria (the group formed of Echinoderms and Hemichordates) (Philippe et al., 2011). If Xenacoelomorpha represents the earliest offshoot of the bilaterians, understanding the evolution of its NS will 


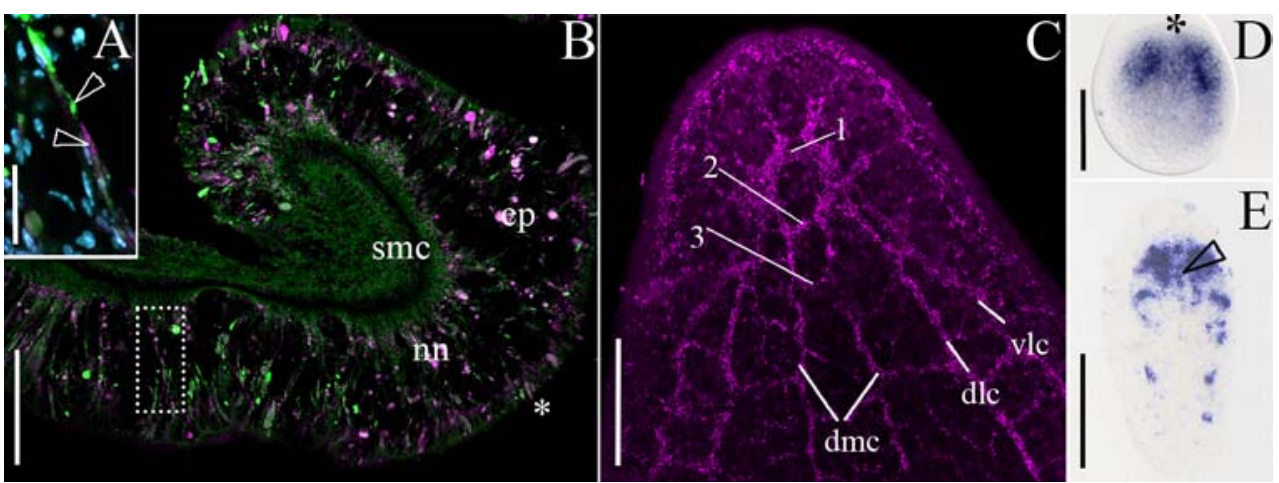

Fig. 1. The nervous systems of the acoel Symsagittifera roscoffensis and Xenoturbella bocki as revealed through the use of immunochemical techniques (antibody anti-synaptotagmin) and in situ hybridization (RNA probe for synaptotagmin). A-B - X. bocki (section immunochemistry); C - S. roscoffenis hatchling (whole-mount immunochemistry); D-E - S. roscoffenis (embryo, D; hatchling, E) in situ hybridization with synaptotagmin RNA probe.

Scale bar: A $-40 \mu \mathrm{m}$; B $-200 \mu \mathrm{m}$; C $-100 \mu \mathrm{m}$; D $-60 \mu \mathrm{m}$; E $-100 \mu \mathrm{m}$.

Detailed description of the Panels:

A - magnification of a section of the Xenoturbella's epidermis. The two arrowheads point a neural process (empty arrow in greyscale version) following a muscular fibre (full arrow in greyscale version). Green: phalloidin (musculature); Pink: Stg antibody (nervous system). B - cross-section of Xenoturbella: ep — epidermal layer; nn — nervous system; smc subepidermal membrane complex. Asterisk (*) indicates the exterior of the animal. A magnification of the rectangular area is seen in detail (panel A). C - adult head of the acoel S. roscoffensis labelled with the anti-Stg antibody. Numbers $1,2,3$ - main commissures of the brain; dlc - dorso-lateral cords; dmc — dorso-medial cords; vlc — ventro lateral cords. D - colorimetric in situ hybridization (ISH) assays for the detection of the mRNA of the neural marker synaptotagmin at, approx. 24-48 h post-fertilization. The asterisk (*) indicates the position of the anterior pole of the embryo. E - ISH of a juvenile, 24-48 h after hatching. The arrowhead points to the position of the statocyst. The anterior part is always up.

be fundamental to explain the origin of bilaterians; and in a good part, the radial-bilateral transition (RBT). In contrast, if Xenacoelomorpha represents a basal deuterostome taxon, the analysis will be valuable to understand the origin and evolution of deuterostomes, when a significant body plan reorganization also occurred. All in all, our interest is the origin of the brain as a complex anatomical structure.

\section{The nervous system of Xenacoelo- morpha}

For a long time it was assumed that the use of different morphological characters allowed making solid statements regarding the specific phylogenetic affinities of different clades. One set of characters that has regularly been used in Xenacoelomorpha and other groups of animals is the neuroanatomical characters. We have already noted elsewhere that the architecture of the NS within the Xenacoelomorpha shows a clear pattern of diversification in which more basal groups have, largely, nerve nets and more recently diverging groups show clear ganglionic structures (Achatz, Martinez, 2012) (see also Fig. 2, obtained from: Perea-Atienza et al., 2015). Our current data shows that members of Xenoturbellida possess the simplest adult neuroanatomical organization and ultrastructure of the Xenacoelomorpha, and probably one of the simplest of all adult bilaterians. This NS is organized as a complete intraepidermal nerve net (see Fig. 1) with interwoven neuronal fibres (Raikova, 2004). A pattern of diversification of NS compatible with more recent groups showing centralized architectures is observable in the Acoelomorpha, the sister group of the Xenoturbellida. In some Acoelomorpha species, we can see the first obvious neural aggregations positioned in the most anterior part of the body. In the Nemertodermatida class, the NS has been 


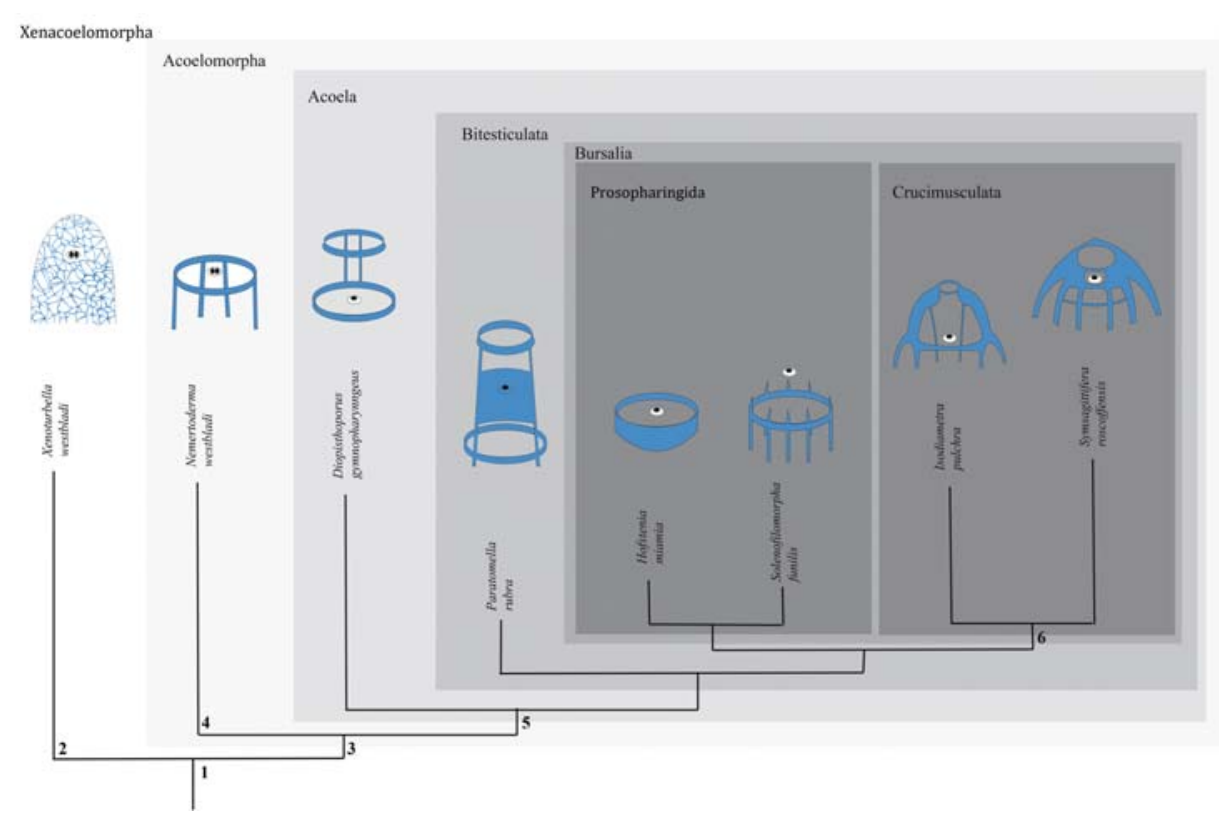

Fig 2. Schematic view of different xenacoelomorph nervous system architectures. The diversity of nervous systems is epitomized in the changes seen between the nerve net of the xenoturbellids (left) and the compact brains of the acoels belonging to the class Crucimusculata (right). The diagram is taken from Perea-Atienza et al. (2015).

studied using light microscopy in Nemertoderma westbladi (Westblad, 1937); by electron microscopy in Nemertoderma sp. (Ehlers, 1985) and Flagellophora apelti; and in later studies through the use of GYIRFamide, FMRFamide, tyrosinated-tubulin and 5-HT immunoreactivity in Nemertoderma westbladi and Meara stichopi (Børve, Hejnol, 2014; Raikova et al., 2004). According to those studies, the NS of nemertodermatids consists of a basiepidermal plexus that is slightly concentrated in the anterior part of the body. The two species described in most detail, $N$. westbladi and M. stichopi, present different degrees of NS centralization. $N$. westbladi possesses a broad ring of neurites located anteriorly and outside the body wall musculature, with a higher density of processes and cell bodies on the dorsal side. In Meara stichopi, the arrangement of the NS is slightly different: a commissure connects the only two longitudinal nerve cords (Raikova et al., 2000; Børve, Hejnol, 2014), which run below the muscles and along the whole body length. Where the more centralized NS architectures in recent groups (as opposed to early diverging ones) are seen most clearly within Xenacoelomorpha, is in the acoels (particularly in the class Crucimusculata). In fact, the acoels' NS is characterized by its high plasticity, which is evident in the very different neuronal arrangements that these species exhibit. A quick comparison of, for instance, acoels belonging to the most basal family (Diopisthoporidae) and those of the most divergent families within the class Crucimusculata reveals very striking differences in neural system arrangement (Jondelius et al., 2011; Achatz, Martinez, 2012). Whereas in the most basal groups the nervous system is organized as a ring of processes in the area around the statocyst, in Crucimusculata, the most "advanced" (recently diversified) acoels, the NS is organized as a compact ganglionic brain, with a dense neuropile surrounded by numerous cellular bodies (Fig. 2). Using the knowledge generated through several studies, old and new, for the first time we are in a position to understand the morphological evolution of the NS within the phylum Xenacoelomorpha, as a starting 


\section{S. roscoffensis juvenile}

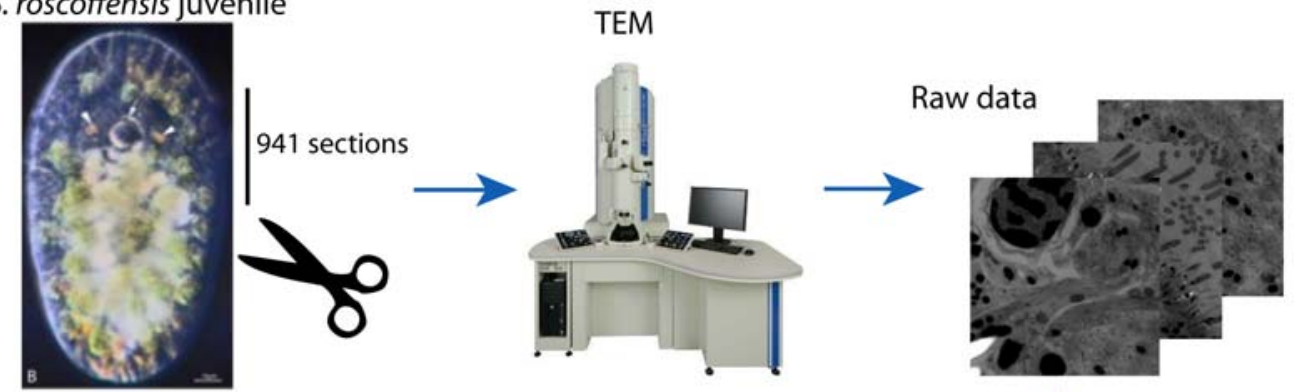

TrakEM2 software (A. Cardona, Janelia Farm, USA)

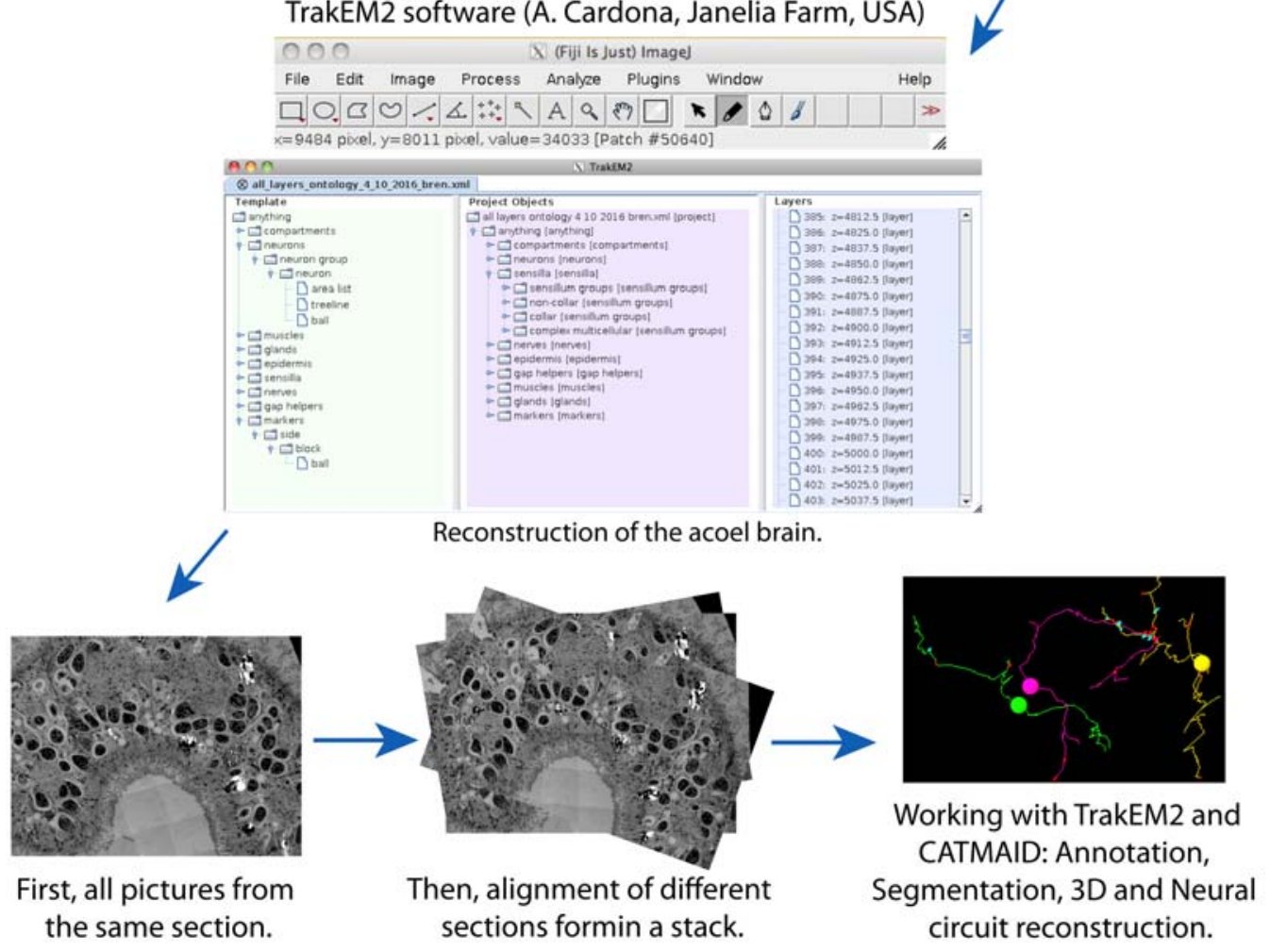

Fig. 3. A flow diagram showing the procedure taken for a complete reconstruction of the acoel Symsagittifera roscoffensis juvenile nervous system. Images from serial TEM sections are annotated and used for a full reconstruction using the software packages TrackEM2 and CATMAID.

point to study the evolutionary developmental mechanisms underlying the origin, centralization and diversification of animal brains. The use of methodologies that allow the detailed characterization of all cellular elements in a nervous system, via the systematic use of TEM and image reconstruction methods is giving us first detailed insights on the fine structure of the acoel nervous system (see Bery et al. (2010), Saalfeld et al. (2009) and the diagram in Fig. 3). 


\section{Neurogenic genes in Xenacoelo- morpha}

Very little is known of the genes that control neurogenesis in Nemertodermatida and Xenoturbellida. For this reason, this section focuses on the molecular control of neurogenesis in those acoel species that have been most studied. Acoel development follows a special cleavage pattern called "duet cleavage" (Henry et al., 2000). The ectodermal cells (which give rise to epidermal and neural cells) are derived from the 4-cell stage animal pole micromeres. Later on in development, the progeny of those micromeres that will differentiate into neurons become internalized and soon start expressing the SoxB gene: a pro-neural marker present in several bilaterian and non-bilaterian species (Hejnol, Martindale, 2008). Although much information on the genes that trigger the initial steps of neural commitment and differentiation is still lacking (but see: Ramachandra et al. (2002)), most of our current knowledge corresponds to analysis of AP patterning in the acoel NS. In all the species studied, only three Hox genes have been identified: one anterior, one central and one posterior (Moreno et al., 2009). As development proceeds, these genes seem to provide the needed positional information to the newborn neurons. A few other 'classical' neural genes have been studied in the acoel Convolutriloba longifissura. For instance, the orthologue of the posterior ParaHox gene caudal/ $C d x$ (expressed in many bilaterian neural domains) is also expressed anteriorly in juvenile neural structures, most probably in the cells that also express the neural genes NK2.1 and Otp (Hejnol, Martindale, 2008).

Our understanding of the genetic control of neurogenesis in acoels (or in the xenacoelomorphs) is clearly still very limited. Efforts should be made to identify and characterize many more genes involved in this process that will lead us to understand how neurogenic gene networks have evolved within this phylum, and how these changes relate to the inherent structural complexity of their NS.
In the next few sections we provide a review of our current efforts to characterize the genomic and transcriptomic basis underlying the developmental construction and the adult morphology of the xenacoelomorph nervous systems. We want to bring to the forefront the research strategies that are being implemented in order to understand how brains have evolved in this particular group (phylum), a concrete example of how brains might have originated, independently, over evolutionary time in other clades (see: Northcutt (2012) for a general appraisal).

\section{Sequencing and annotation of Xe- nacoelomorpha genomes}

Over the last few years, within the international consortium in charge of sequencing diverse Xenoacelomorpha genomes, our group has been involved in the analysis of genomic sequences, with special focus on the annotation of families of transcription factors and other developmental regulators. As the only group able to collect, culture and isolate nucleic acids from some acoel flatworms, we have been key participants. The genome of $S$. roscoffensis had a size of $1.4 \mathrm{Gbp}$ (through flow cytometry): much larger than that of Xenoturbella, which is about 150-200 Mbp (from the genome assembly). These two genomes have provided the best sequences. All the other xenacoelomorphs have provided sequences of poorer quality, since they are very small and rare animals, and all their DNAs had to go through a process of preamplification; this results in poorer quality of the final assembled scaffolds. At present, the N50 value for the Xenoturbella genome was about $20 \mathrm{Kbp}$ while the Symsagittifera was somewhat more than $3 \mathrm{Kbp}$. The quality of the assemblies was determined through comparison with the total number of ESTs obtained for both species. The annotated genes are now used to reanalyse, using phylogenomic techniques, the phylogenetic position of this group within the metazoan tree of life. Needless to say, we are also looking at the structure of the genome, 
intron/exon, presence of repetitive elements, transposons, microRNAs, etc.

To gain a more complete view of the Xenacelomorpha genomes, we have also initiated the sequencing of genomes from other members of this phylum, for instance Paratomella rubra (a basal acoel taxon; leader: Max Telford, UCL, UK), the acoel Praesagittifera naikaiensis (leader: Noriyuki Satoh; OIST, Japan), and the nemertodermatid Nemertoderma westbladii.

\section{Initial identification of putative "neurogenic" genes in the Xenacoelo- morpha}

In order to collect preliminary data for this new project, we began the search for two major groups of transcription factor genes: the homeobox-and the basic helix-loop-helix (bHLH)containing families (Jones, 2004). Initial analysis has shown that Xenacoelomorpha have a reduced complement of the bHLH families, all involved in tissue specification, mainly neural and mesodermal (Perea-Atienza et al., 2015). We have identified 18 different members in the acoel Symsagittifera and 33 in Xenoturbella. Interestingly, in both animals we have detected orthologues of the major neurogenic-regulatory families, including Achaete-Scute or NeuroD. However, we noticed the absence in Symsagittifera of some well-known relatives, such as those belonging to the families Atonal, Hand, or Neurogenin, suggesting a less complex regulatory apparatus dedicated to patterning the acoel NS. This is surprising since superficially the NS of Xenoturbella is simpler than that of Symsagittifera. While the Xenoturbella NS is organized as a sub-epithelial net (without obvious cell aggregates: ganglia), the NS of Symsagit- tifera is organized as a compact ganglionic brain. This preliminary observation suggests that similar levels of complexity of the neural regulatory families do not necessarily parallel "simplicity" in the architectural organization of the NS.

During these previous years, we also initiated a thorough characterization of the different members of the G protein-coupled receptor (GPCR) superfamily (Schiöth, Fredriksson, 2005), because this group of proteins controls the transduction of different sensory information (vision, smell, taste, etc.). We analysed the complex families of GPCRs in both Xenoturbella and Symsagittifera. We found that a complement of 304 different GPCR genes resides in the Xenoturbella genome; while in the case of Symsagittifera; this complement is reduced to 245 different sequences (Perea-Atienza et al., 2015). The identification of these GPCR genes together with the bHLH transcription factors was published in 2014. More recently we have identified the whole complement of Wnt ligands (key patterning factors in all bilaterians, Croce, McClay (2008)) in the xenacoelomorphs. Interestingly, we have discovered that while xenoturbellids have $W n t$ genes that are clearly classifiable within bilaterian groups, the acoels seem to have several genes derived from lineage-specific duplication. We are currently using in situ hybridization methods to study their expression patterns in Symsagittifera. These preliminary results of our genome project are shown in Table 1.

In the near future these initial studies should be complemented with the characterization of other families, mostly those families involved in neuronal physiology. This data could reveal other levels of complexity beyond that of the superficial anatomical architecture (see a similar example in cnidarians: Bosch et al. (2017)).

Table 1. A compilation of family members in several families of genes involved in the xenacoelomorph nervous system development and function. Data are obtained from the analysis of Xenoturbella bocki and Symsagittifera roscoffensis genome sequences (Fritzsch et al., 2007; Moreno et al., 2009; Perea-

Atienza et al., 2015; Gavilán et al., 2016).

\begin{tabular}{|l|c|c|c|c|}
\hline Species & Hox & Wnts & bHLHs & GPCRs \\
\hline Xenoturbella bocki & 5 & $11(12 ?)$ & 33 & 258 \\
\hline Symsagittifera roscoffensis & 3 & 5 & 18 & 225 \\
\hline
\end{tabular}




\section{Expression of neural patterning genes from the bHLH and homeobox- containing families}

Over the last year, we have been working on the analysis of expression patterns by in situ hybridization of the acoel bHLH-and homeoboxcontaining transcription factors. We are also developing protocols for double fluorescence in situ hybridization and combined in situ hybridization plus immunochemistry (mRNAs and proteins detected at the same time). We only have preliminary data for most of the genes, but the most interesting observation has been that while genes such as NK2.1, Otx, Six3 and Hox 1 show staggered domains of expression along the major body axis, in acoels their domains all overlap in the most anterior part of the body (in the brain area). This is a surprising result since it seems to indicate that these patterning genes are used in a "collapsed" fashion compared to what is seen in most bilaterians (even in the cnidarian Nematostella!). More homeobox genes have to be analysed to obtain a detailed cartography of regulatory gene expression in the brain of acoels. We have also analysed the pattern of expression of all bHLH genes in embryos and juveniles of S. roscoffensis. Interestingly a fraction of them seem to be expressed in different neural domains, subdividing the nervous systems in areas with specific combinations of bHLHs. The fact that they are expressed in early embryogenesis points to the putative neurogenic roles, or the regulation of the early specification of neural lineages (data unpublished; to be presented at ICIM4). We also aim to map some of the genes in nemertodermatids. For this particular reason we have collected specimens of Nemertoderma westbladii in the coastal waters of Sweden. We hope that a similar detailed study of nemertodermatid gene expression will provide us with a view of gene regulatory evolution in the Acoelomorpha NS.

\section{The adult context: regeneration studies in $S$. roscoffensis}

A very interesting fact we discovered in the last couple of years is that $S$. roscoffensis is able to regenerate the anterior part of its body, including a complete brain, from scratch (Sprecher et al., 2015). In the last years we started characterizing the process, looking at the regeneration process using commercial (and now our own) neural antibodies. We have also started looking at the contribution of stem cells (neoblasts) in the newly regenerated structures. We aim to analyse this, and over the coming years also the use of neurogenic genes (from the bHLH and homeobox families) during the regeneration process, with the objective of understanding their putative roles in organizing a new functional brain. This will inform us of the functional recovery of the NS, in parallel to the structural reconstruction of this structure. A parallel investigation using behavioural tests has uncovered some basic aspect of the recovery of neural functions in the brain of Symsagittifera roscoffensis (Sprecher et al., 2015). These experiments should provide us with a unique opportunity to use new approaches to understand key functional aspects of the acoel nervous system (see also Franks et al. (2016)).

\section{From nerve nets to compact brains: a hypothesis}

Several authors have proposed that the most rudimentary nervous systems had the architecture of a nerve net (Parker, 1919; Northcutt, 2012), a configuration of neurons that receives sensory input and processes locomotor or neurosecretory output only locally, without central integration (Arendt et al., 2008). Thus, the more complex, centralized, nervous system derived from well-interconnected elements that became more concentrated in an area at the forefront of the individual. Whether this has happened only once or multiple times throughout the history of evolution on Earth is a matter of debate (Moroz, 2012; Northcutt, 2012; Gavilán et al., 2016). However, a mapping of taxa with one or the other form of nerve system architecture (characters) in a phylogenetic tree suggests that compact nervous systems have originated in several different lineages inde- 
pendently. We may wonder how that could have happened: is the construction of a compact brain not an excessively "big deal" for it to have occurred more than once? Here we hint at some possible answers.

Our hypothesis (shared with others) is that compact brains arise in the context of more complex ecologies: when animals have to deal with more complex environments, including the need for complex behavioural repertoires (that may derive from predatory challenges or sexual selection forces). Nerve nets meet the requirements of survival and navigation in relatively simple environments, where directional challenges are, relatively speaking, less important. Centralized nervous systems appear in the context of anisotropic environmental challenges: when it is an advantage to compute clearly directional inputs and to respond to them. In such conditions, directional responses towards (anisotropic) outside signals eventually become critical for the survival of the species. We would like to suggest (along the lines of the proposal by Parker (1919)) that the driving force behind one centralization process was the potential advantage to be gained by reacting to the preferential localization of some receptors in the frontal part of the organism (any kind of receptor: light, chemical, mechanic, etc.). This original asymmetry forced the displacement of neural elements towards the area where the receptors were located (a simple matter of saving wire and thereby decreasing the use of metabolic resources). Due to positive feedback, this initial process was then followed by a recurrent increase of receptor structures in the same area of the brain and the subsequent further elaboration of this central processing unit (a brain proper). The balance between needs and energy costs would have modulated the architecture and complexity of the different (taxa's) brains. We suggest here that the initial event that might have triggered the feedback process could have been a variable number and/or location of receptors around the animal body. This could have created differential numbers of receptors at the anterior part of the body, an event that in the presence of selective forces could have been the tipping point from which the cascade of subsequent events happened. The model we propose (see Fig. 4) is formulated as the "Receptor and Neuronal Aggregation Hypothesis (RNA Hypothesis)".

The movement of neural structures towards the front of the individual should not be a complex process. We know that nerve nets, such as those present in the hemichordates (Pani et al., 2012), use the same general patterning system as compact brains do (i.e. those of vertebrates). This suggests that the blueprint for the formation of the compact brain is already present in ancestral relatives equipped with nerve nets. It is, most probably, "just" a matter of regulating the relative expression domains of some of the regulators in the pattern (moving the domains along the body axes) to achieve a different architectural disposition of neurons in any area of the body. Perhaps the receptors themselves, or the receptor area, can provide direct information to the cis-regulatory apparatuses of the patterning genes, thereby directing their expression domains to produce a tendency toward a specific spatial location. If control of the proliferation of precursors is added, then size can be modified (in toto or in a specific area of the brain). Thus a coordinated rearrangement of the spatial domains of expression of pattern regulators plus tight control of the proliferative activities of neural precursors could generate compact brains of variable size. The layout of the model, that we called Receptor and Neural Aggregation Hypothesis (RNA), is presented in Figure 4. We are aware that in this hypothesis the contact between nerve cells and muscles (the neuromotor) system is not considered. The inclusion of target cells/tissues will be incorporated in further versions of this model.

Needless to say this is a hypothesis, or a set of hypotheses, that is not easy to test but certainly is amenable to some experimental checks in groups with variable neural architectures, such as the Xenacoelomorpha (our main experimental system). 


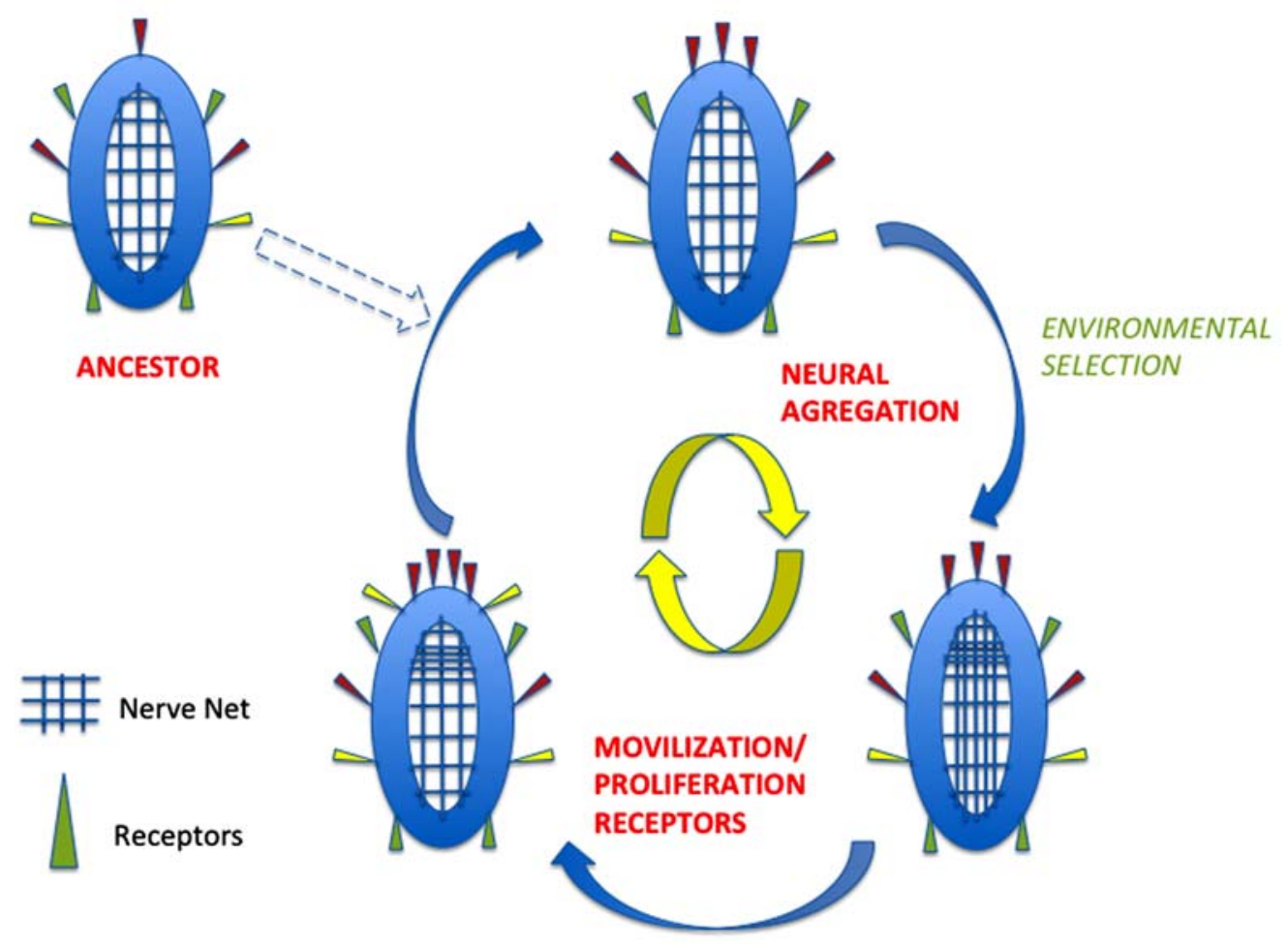

Fig. 4. The Receptor and Neuronal Aggregation Hypothesis (RNA). The diagram sketches the basic tenets of the hypothesis we suggest for the origin of centralized nervous systems from nerve net like ancestors. A positive feedback loop between the localized expression of receptors in the anterior of the body and the progressive aggregation of interconnected neurons in their proximity lies at the core of the hypothesis. Successive rounds of the loop consolidate compact structures such as the brain. Patterning genes dictate the position and the 3D structure of the aggregate.

\section{Conclusion}

A fundamental problem in the evolutionary history of animals is the origin and diversification of nervous systems. It is assumed that centralized nervous systems (brains) have originated from more or less extensive nerve nets, by a process (or processes) that is currently unknown. One of the best examples of centralization occurs in the clade (phylum) Xenacoelomorpha, where different members of this clade show a great variety of nervous systems architectures, from the simple nerve net of xenoturbellids to the more compact brains of the acoel class Crucismusculata. The molecular mechanisms underpinning this transition, from nerve net to compact brains needs to be characterized, an endeavour we have taken in our groups over the last few years. A major focus in this research has been the characterization of genes and expression patterns of putative regulators of neurogenesis in Xenoturbella bocki and Symsagitiffera roscoffensis, our major reference species. This characterization has been carried out in parallel to a deep study of the architecture of the nervous systems in these members of the Xenacoelomorpha. The combined morphological and genomic study of those species is providing us, for the first time, with clear insights on the genetic basis of neurogenesis members of the phylum Xenacoelomorpha. The ultimate goal is that of illuminate the process of nervous 
system centralization occurring within this phylum; one of several, and perhaps the first, major centralization events that occurred in Bilateria. We are aware, though, that categorizing nervous systems as "centralized" is also complicated (cnidarian medusa have also nerve rings with elaborated architectures). This project benefits from the recent sequencing of their genomes. The preliminary data suggest some interesting correlations occurring within this phylum, for instance the inverse correlation between the complexity of nervous systems and the diversity of proteins families linked to the development and function of the nervous system. Seemingly simpler nervous systems, epitomized in the case of Xenoturbella have richer complements of "neurogenic" genes than more complex, centralized, nervous systems (for instance in the acoel $S$. roscoffensis). Understanding whether these correlations are of functional significance will be a key objective for the near future.

\section{Acknowledgements}

P.M. acknowledges the support from the Spanish Ministry ofEconomy (MINECO), Grant Number BFU2009-07383. S.G.S. acknowledges the support by the Swiss National Science foundation (Grant 31003A 169993) and the European Research Council (ERC-2012-StG 309832-PhotoNaviNet).P.M. and S.G.S. would like to thank the University of Gothenburg for the funds provided by the program to support internationalization and scientific renewal at the Sven Lovén Centre for Marine Sciences (Kristineberg).

\section{References}

Achatz J.G., Chiodin M., Salvenmoser W., Tyler S., Martinez P. 2013. The Acoela: on their kind and kinships, especially with nemertodermatids and xenoturbellids (Bilateria incertae sedis) // Org. Div. Evol. Vol.13. No.2. P.267-286.

Achatz J.G., Martinez P. 2012. The nervous system of Isodiametra pulchra (Acoela) with a discussion on the neuroanatomy of the Xenacoelomorpha and its evolutionary implications // Front. Zool. Vol.9. No.1: 27

Arendt D., Denes A.S., Jékely G., Tessmar-Raible K. 2008. The evolution of nervous system centralization
// Philos. Trans. Roy. Soc. Lond. Ser.B. Biol. Sci. Vol.363. No.1496. P.1523-1528

Børve A., Hejnol A. 2014. Development and juvenile anatomy of the nemertodermatid Meara stichopi (Bock) Westblad 1949 (Acoelomorpha) // Front. Zool. Vol.11. No.50.

Bosch T.C.G., Klimovich A., Domazet-Lošo T., Gründer S., Holstein T.W., Jékely G., Miller D.J., MurilloRincon A.P., Rentzsch F., Richards G.S., Schröder K., Technau U., Yuste R. 2017. Back to the Basics: Cnidarians Start to Fire // Trends in Neurosciences. Vol.40. No.2. P.92-105.

Bourlat S.J., Juliusdottir T., Lowe C.J., Freeman R., Aronowicz J., Kirschner M., Lander E.S., Thorndyke M., Nakano H., Kohn A.B., Heyland A., Moroz L.L., Copley R.R., Telford M.J. 2006. Deuterostome phylogeny reveals monophyletic chordates and the new phylum Xenoturbellida // Nature. Vol.444. No.7115. P.85-88.

Croce J.C., McClay D.R. 2008. Evolution of the Wnt Pathways // Methods in molecular biology. Clifton, N.J. Vol.469. P.3-18.

Ehlers U. 1985. Das Phylogenetische System der Plathelminthes. Stuttgart: Gustav Fischer.

Franks N.R., Worley, A., Grant K.A.J., Gorman A.R., Vizard V., Plackett H., Doran C, Gamble M.L, Stumpe M.C., Sendova-Franks A.B. 2016. Social behaviour and collective motion in plant-animal worms // Proc. Roy. Soc. Ser.B. Biol. Sci. Vol.283. No.1825: 20152946.

Fritzsch G., Böhme M., Thorndyke M., Nakano H., Israelsson O., Stach T., Hankeln T., Stadler P. 2007. PCR survey of Xenoturbella bocki Hox genes // J. Exp. Zool. Ser.B. Mol. Dev. Evol. Vol.15. No.310. P.278-284.

Gavilán B., Perea-Atienza, E., Martínez, P. 2016. Xenacoelomorpha: a case of independent nervous system centralization? // Phil. Trans. Roy. Soc. Lond. Ser.B. Biol. Sci. Vol.371. No.1685: 20150039

Hejnol A., Martindale M.Q. 2008. Acoel development indicates the independent evolution of the bilaterian mouth and anus // Nature. Vol.456. No.7220. P.382386.

Hejnol A., Obst M., Stamatakis A., Ott M., Rouse G.W., Edgecombe G.D., Martinez P., Baguñà J., Bailly X., Jondelius U., Wiens M., Müller W.E., Seaver E., Wheeler W.C., Martindale M.Q., Giribet G., Dunn C.W. 2009. Assesing the root of bilaterian animals with scalable phylogenomic methods // Proc. Biol. Sci. Vol. 276. No.1677. P.4261-4270.

Israelsson O. 1999. New light on the enigmatic Xenoturbella (phylum uncertain): ontogeny and phylogeny // Proc. Biol. Sci. Vol.266. No.1421: 835.

Jondelius U., Wallberg A., Hooge M., Raikova O.I. 2011. How the worm got its pharynx: phylogeny, classification and Bayesian assessment of character evolution in Acoela // Syst. Biol. Vol.60. No.6. P.845-871.

Jones S. 2004. An overview of the basic helix-loop-helix proteins // Genome Biol. Vol.5. No.6: 226.

Lundin K. 1997. Comparative ultrastructure of the epidermal ciliary rootlets and associated structures in spe- 
cies of the Nemertodermatida and Acoela (Plathelminthes) // Zoomorphology. Vol.117. No.2. P.81-92.

Lundin K. 2000. Phylogeny of the Nemertodermatida (Acoelomorpha, Platyhelminthes). A cladistic analysis. Zoologica Scripta. Vol. 29. No.1: 65-74

Lundin K., Hendelberg J. 1995. Ultrastructure of the epidermis of Meara stichopi (Platyhelminthes, Nemertodermatida) and associated extra-epidermal bacteria // Biology of Turbellaria and some Related Flatworms. Dordrecht: Springer Netherlands. P.161165.

Moreno E., Nadal M., Baguñà J., Martínez P. 2009. Tracking the origins of the bilaterian Hox patterning system: insights from the acoel flatworm Symsagittifera roscoffensis // Evol. Dev. Vol.11. No.5. P.574581.

Moroz L. 2012. Phylogenomics meets neuroscience: How many times might complex brains have evolved? // Acta Biol Hung. Vol.63. Suppl.2. P.3-19.

Northcutt R.G. 2012. Evolution of centralized nervous systems: Two schools of evolutionary thought // Proc. Natl. Acad. Sci. U.S.A. Vol.109. Suppl.1. P.1062610633.

Pani A.M., Mullarkey E.E., Aronowicz J., Assimacopoulos S., Grove E.A., Lowe C.J. 2012. Ancient deuterostome origins of vertebrate brain signalling centres // Nature. Vol.483. No.7389. P.289-294.

Parker G.H. 1919. The elementary nervous system. Philadelphia: J.B. Lippincott Company.

Perea-Atienza E., Gavilán B., Chiodin M., Abril J.F., Hoff K.J., Poustka A.J., Martinez P. 2015. The nervous system of Xenacoelomorpha: a genomic perspective // J. Exp. Biol. Vol.15. No.218. P.618-628.

Raikova O.I. 2004. Neuroanatomy of basal bilaterians (Xenoturbellida, Nemertodermatida, Acoela) and its phylogenetic implications ( $\mathrm{PhD}$ Thesis). Abo Akademi University.

Raikova O.I., Reuter M., Gustafsson M.K.S., Maule A.G., Halton D.W., Jondelius U. 2004. Basiepidermal nervous system in Nemertoderma westbladi (Nemerto- dermatida): GYIRFamide immunoreactivity // Zoology. Vol.107. No.1. P.75-86.

Raikova O.I., Reuter M., Jondelius U., Gustafsson M.K.S. 2000. The brain of the Nemertodermatida (Platyhelminthes) as revealed by anti-5HT and anti-FMRFamide immunostainings // Tissue \& Cell. Vol.32. No.5. P.358-365.

Ramachandra N.B., Gates R.D., Ladurner P., Jacobs D.K., Hartenstein V. 2002. Embryonic development in the primitive bilaterian Neochildia fusca: Normal morphogenesis and isolation of POU genes Brn-1 and Brn-3 // Dev. Genes Evol. Vol.212. No.2. P.55-69.

Rouse G.W., Wilson N.G., Carvajal J.I., Vrijenhoek R.C. 2016. New deep-sea species of Xenoturbella and the position of Xenacoelomorpha // Nature. Vol.530. No.7588. P.94-97.

Saalfeld S., Cardona A., Hartenstein V., Tomancak P. 2009. CATMAID: collaborative annotation toolkit for massive amounts of image data // Bioinformatics. Vol.25. No.15. P.1984-1986.

Schiöth H.B., Fredriksson R. 2005. The GRAFS classification system of G-protein coupled receptors in comparative perspective // Gen. Comp. Endocrinol. Vol.142. No.1-2. P.94-101.

Smith J.P.S., Tyler S. 1986. Frontal organs in the Acoelomorpha (Turbellaria): ultrastructure and phylogenetic significance // Hydrobiologia. Vol.132. No.1. P.71-78.

Sprecher S.G., Bernardo-Garcia F.J.L., Hartenstein V., Reichert H., Neves R., Bailly X., Martinez P., Brauchle M. 2015. Functional brain regeneration in the acoel worm Symsagittifera roscoffensis // Biol. Open. Vol.12. P.1688-1695.

Meyer-Wachsmuth I., Curini Galletti M., Jondelius U. 2014. Hyper-cryptic marine meiofauna: species complexes in Nemertodermatida // PLoS One. Vol.16. No.9(9):e107688

Westblad E. 1949. Xenoturbella bocki n.g., n. sp., a peculiar, primitive turbellarian type // Ark. Zool. Vol.1. P.3-29.

Responsible editor E.N. Temereva 